\title{
Модуляционная неустойчивость и параметрическое усиление в световодах с изменяющейся по длине дисперсией
}

\author{
Ю.А. Мажирина ${ }^{1}$, Л.А. Мельников ${ }^{1}$, А.А. Сысолятин ${ }^{2, *}$ \\ ${ }^{1}$ Саратовский государственный технический университет имени Гагарина Ю.А. \\ ${ }^{2}$ Институт общей физики РАН им. А.М. Прохорова \\ *E-mail: alex@fo.gpi.ru
}

DOI: 10.31868/RFL2020.101-102

Параметрическое усиление тесно связано с модуляционной неустойчивостью - генерацией боковых спектральных компонент при распространении в оптическом волокне с керровской нелинейностью излучения с постоянной интенсивностью. Для модуляционной неустойчивости необходимы определенные соотношения между дисперсией групповой скорости в волокне, частотой отстройки модуляционной компоненты от частоты поля накачки и коэффициентом нелинейности волокна[1]. Если волокно, вследствие модуляции диаметра, имеет дисперсию, зависящую от продольной координаты, то условия усиления боковых компонент будут различны в различных точках волокна, и условия генерации боковых компонент могут измениться. Однако, было показано, что модуляционная неустойчивость существует и в волокнах с переменным диаметром [2,3]. В докладе представлены результаты расчета спектра параметрического усиления в волокне с переменной дисперсией. Решается $\quad$ НУШ: $\quad 2 i \frac{\partial A(z, t)}{\partial z}-D(z) \frac{\partial^{2} A(z, t)}{\partial t^{2}}+2 \alpha A^{2}(z, t) A^{*}(z, t)=0, \quad$ где $D=-\frac{\lambda}{c} \frac{\partial^{2} n_{\text {эфф }}}{\partial \lambda^{2}}$ - параметр, ответственный за дисперсию групповой скорости (ДГС), $n_{\text {эфф }}$ - эффективный показатель преломления волокна. Малые отклонения амплитуды поля имеют вид

$$
A(z, t)=A_{0}(z, t)\{1+[x(z) \exp [i y(z)]] \cos (\Omega t)\} .
$$

Здесь $A_{0}(z, t)=\sqrt{P} \exp [i \alpha P z]$ - решение НУШ для пучка накачки с постоянной интенсивностью. Здесь $\alpha$ - коэффициент нелинейности волокна, $P$ интенсивность накачки, $\Omega$ - отстройка частоты боковой компоненты от частоты накачки. Уравнения для $x$ и $y$ получаются в виде[2]:

$$
\begin{aligned}
& x^{\prime \prime}+K^{2}(z) x-Q(z) x=0 . \\
y^{\prime}= & {\left[\Omega^{2} D(z)+P \alpha\right] x(z), K^{2}=1 / 4 \Omega^{4} D^{2}(z)+P \alpha \Omega^{2} D(z), Q(z)=D^{\prime}(z) / D(z) . }
\end{aligned}
$$

Если учесть $D(z)=D_{0}+d \cos (\kappa z)$, где $\kappa$ - частота модуляции дисперсии, $d$ амплитуда модуляции, $D_{0}$ - средняя дисперсия, то уравнение для $x$ является уравнением с периодическими коэффициентами и может быть сведено к уравнению Матье[3,4]: $a-2 q \cos (2 z)=K^{2}(z)-Q(z)$. В нём $a$ и $q$ - параметры в уравнении Матье. Определим инкремент нарастания возмущений $g=2 / z_{0} \log \left[x\left(z_{0}\right) / x(0)\right]$, где $z_{0}$ - достаточно большая длина (можно положить $\mathrm{z}_{0}=4$, которая измеряется в дисперсионных длинах). 
На Рис.1 показана зависимость $K^{2}(z, \Omega)$. Видно, что в среднем $K^{2}>0$, что соответствует осциллирующим возмущениям. Если $K^{2}<0$, то это приводит к нарастанию возмущений. На Рис.2 а показан инкремент нарастания возмущений в зависимости от частоты. Видно, что в отсутствие дисперсионных изменений существует область усиления (модуляционной неустойчивости) шириной в несколько ТГц, которая также соответствует параметрическому усилению. При этом даже при положительной дисперсии существует область модуляционной неустойчивости (Рис.2 б). Эта область отсутствует при $d=0$.

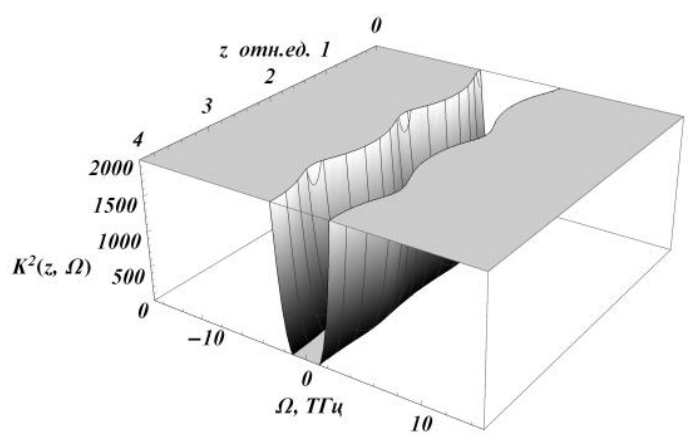

a)

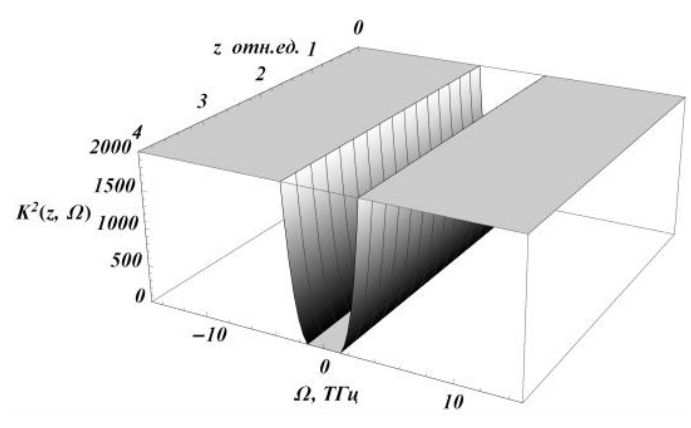

б)

Рис.1. Зависимость $K^{2}(z, \Omega)$ построена для параметров $D_{0}=-10 n c /\left(\mathrm{HM}^{*} \kappa \mathrm{k}\right)$; a)d $=4, \sigma) d=0 ; \kappa=2 / \pi ; \alpha P=8$.

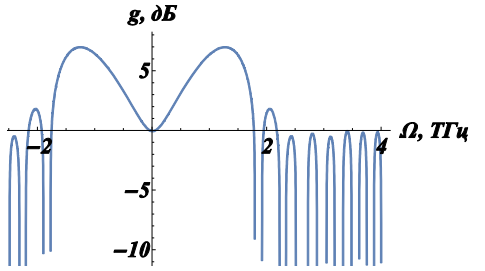

a)

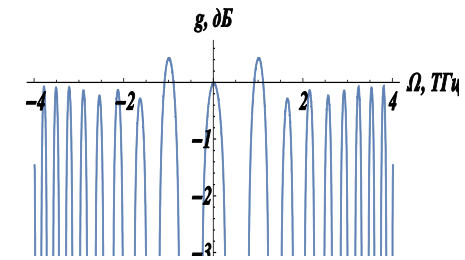

б)

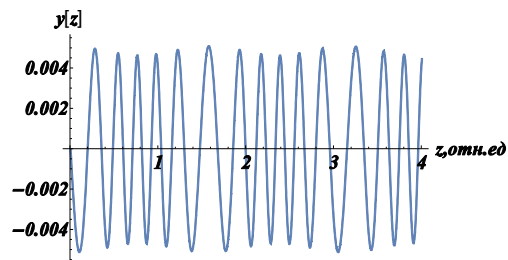

в)

Рис.2. а) Зависимость инкремента нарастания боковых компонент $g(\Omega)$ для параметров как на Рис. 1 ; б) то же, кроме $D_{0}=10 n c /\left(\mu M^{*} \kappa M\right) ;$ в) Фаза возмущения у(z), параметры, как на Рис. 1.

В данной работе показано, что модуляционная неустойчивость, а следовательно, и параметрическое усиление существуют и в волокнах с положительной ДГС. Для этого необходима модуляция дисперсии по длине волокна. Параметрическое усиление сигнала сопровождается незначительным, порядка $10^{-3}$ рад, фазовым шумом (члены с у(z) в (2)).

Работа поддержана грантом РФФИ № 19-52-45012 .

\section{Литература}

[1] G.P. Agraval. Nonlinear Fiber Optics. Waltham: Academic Press, 648c (2013).

[2] Л.А.Мельников, Ю.А.Мажирина. Квантовая электроника 47, 1083-1090 (2017)

[3] C.Finot, A. Sysolyatin et al. Optics Communs 348, 24-30 (2015).

[4] M. Abramowitz, I. Stigun. Special Functions handbook. Applied Mathematics Series, 55, National Bureau of Standards, (1964). 